\title{
Decimeter-scale in situ mapping of modern cross-bedded dune deposits using parametric echo sounding: A new method for linking river processes and their deposits
}

\author{
Gregory H. Sambrook Smith, ${ }^{1}$ James L. Best, ${ }^{2}$ Oscar Orfeo, ${ }^{3}$ Mark E. Vardy, ${ }^{4}$ \\ and Jessica A. Zinger ${ }^{5}$
}

Received 10 May 2013; revised 27 June 2013; accepted 27 June 2013.

[1] Collecting high-resolution data to quantify the sedimentary architecture within contemporary alluvial channels remains one of the outstanding challenges in fluvial sedimentology. Here, we present data collected using a new geophysical method, the parametric echo sounder (PES), which can meet this challenge. From surveys over a field of sand dunes in the Río Paraná, Argentina, we demonstrate the unique ability of PES to image the subsurface structure within active channels at a decimetric resolution. These data reveal the bounding surfaces between bars and dunes, as well as the foresets and reactivation surfaces within them. This provides quantitative in situ data for recent work that suggests cross-strata preserved by dunes may be more related to flow depths less than the commonly assumed bankfull level. These surveys demonstrate that PES can provide hitherto unobtainable data from alluvial channels and presents significant opportunities for more detailed coupled studies of fluvial processes and their deposits. Citation: Sambrook Smith, G. H., J. L. Best, O. Orfeo, M. E. Vardy, and J. A. Zinger (2013), Decimeter-scale in situ mapping of modern cross-bedded dune deposits using parametric echo sounding: A new method for linking river processes and their deposits, Geophys. Res. Lett., 40, doi:10.1002/grl.50703.

\section{Introduction}

[2] Quantifying the three-dimensional sedimentary architecture of alluvial successions is a central component of paleoenvironmental reconstructions [Hajek and Heller, 2012] and the prediction of the geometry of sedimentary deposits, which are vital for the characterization of oil, gas, and water reservoirs [Bridge and Tye, 2000; Miall, 2006]. Such quantification is often achieved using a combination of data from ancient sediments, numerical modeling, and knowledge

\footnotetext{
${ }^{1}$ School of Geography, Earth, and Environmental Sciences, University of Birmingham, Birmingham, UK.

${ }^{2}$ Departments of Geology, Geography and Geographic Information Science, Mechanical Science and Engineering and Ven Te Chow Hydrosystems Laboratory, University of Illinois at Urbana-Champaign, Illinois, USA.

${ }^{3}$ Centro de Ecologia Aplicada del Litoral, Corrientes, Argentina.

${ }^{4}$ National Oceanography Centre, Southampton, UK.

${ }^{5}$ Department of Geography and Geographic Information Science, University of Illinois at Urbana-Champaign, Illinois, USA.

Corresponding author: G. H. Sambrook Smith, School of Geography, Earth, and Environmental Sciences, University of Birmingham, Birmingham B15 2TT, UK. (g.smith.4@bham.ac.uk)

(C2013. American Geophysical Union. All Rights Reserved. 0094-8276/13/10.1002/grl.50703
}

of the structure of alluvial successions derived from study of contemporary river channels. In the last 15 years, ground penetrating radar (GPR) has revolutionized quantification of the subsurface sedimentary architecture of modern alluvial sediments [Bridge et al., 1998; Fielding et al., 1999; Best et al., 2003; Wooldridge and Hickin, 2005; Mumpy et al., 2007; Sambrook Smith et al., 2006, 2009] and has resulted in new models of alluvial heterogeneity. However, GPR is often restricted to deployment on exposed bar surfaces and, if used through the water column, often provides data with limited subsurface resolution. Data from within the active channels and submerged areas of modern river channels are thus frequently lacking, impairing our ability to provide a complete characterization of the subsurface sedimentary structure from modern river channels.

[3] Dunes are one of the most common bed forms within all rivers [Best, 2005], and hence their deposits are ubiquitous in the rock record. As a result, analyses of dune cross-strata are commonly used to provide evidence regarding paleoflow velocities and depths [e.g., Bhattacharya and Tye, 2004], which are central to a number of applications within sedimentology and reservoir geology [Bridge and Tye, 2000; Lunt et al., 2013]. Given the importance of such estimates, there is a long history of research that has sought to develop theory to establish the controls on the form of dune crossstrata [Paola and Borgman, 1991; Bridge and Best 1997; Leclair et al., 1997; Leclair and Bridge, 2001; Bridge, 2003; Leclair, 2002, 2011]. It is widely accepted that the thickness of dune cross-sets, parallel to the flow, will depend on the: (i) average rate of deposition relative to dune migration rate; (ii) sequence of dune scour depths passing a point through time; and (iii) variability in the shape and celerity of dunes as they migrate. Some of these ideas were encapsulated in a model proposed by Paola and Borgman [1991] that related cross-set thickness to the mean and variance of the bed topography (see Bridge [2003] for a succinct summary). Leclair and Bridge [2001] subsequently adapted this model to generate an expression to allow estimation of the mean dune height from the preserved cross-set thicknesses. This simple tool has been widely adopted and used, with empirical data relating dune height and flow depth, to enable estimation of flow depths that can then be used to provide limits on the overall size of the channel belt [see Bridge, 2003].

[4] Recent work has, however, questioned the utility of some of this past work. For example, Leclair [2011] found that large flows left no clear signature in the deposits of dunes in the Mississippi River, and several studies have reported that dune size does not always scale with flow depth [Best et al., 2007; Leclair, 2011]. A significant issue is that much 


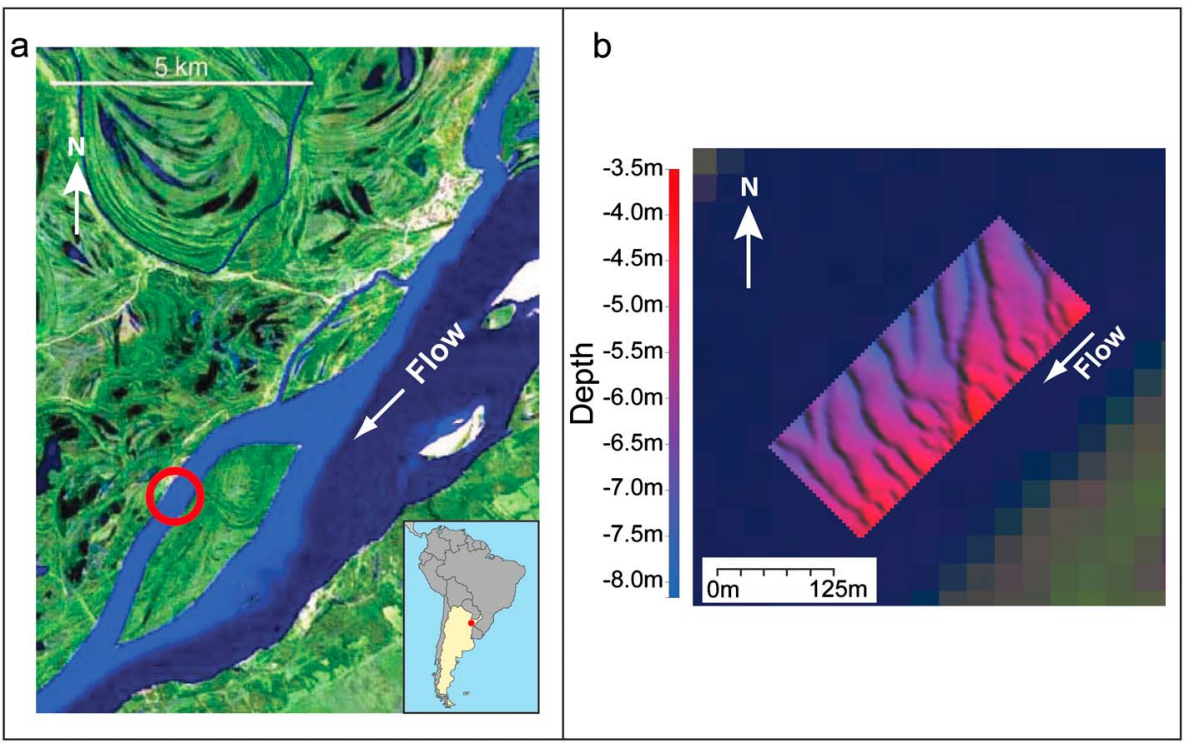

Figure 1. (a) Study site location. (b) Morphology of the dune field as quantified by the parametric echo sounder.

work to test this theory has been based on flume experiments, and there is a paucity of information from large rivers that links dune size with the subsurface cross-set thickness. There is also a growing realization that the more complex three-dimensionality of bed forms and flow processes in natural rivers may require a revision of commonly held principles [Best, 2005]. However, delivering data that quantify the internal stratigraphy of dunes in contemporary rivers is a challenge. For instance, although in marine settings, highresolution seismic systems have been used to provide detail of the internal architecture of dunes [e.g., Ferret et al., 2010], and ground-penetrating radar has been used to provide similar information for large eolian dunes [e.g., Bristow et al., 1996, 2000], river dunes have not yet been studied in such detail. This lack of information is, in part, a technological issue, as seismic acquisition systems traditionally require greater water depths than found in relatively shallow fluvial environments. This limitation has thus resulted in many aspects of dune stratigraphy within modern alluvial channels remaining unknown and unquantified, particularly with respect to their internal three-dimensional architecture because most studies have restricted their consideration only to vertical profiles [Paola and Borgman, 1991; Bridge and Best 1997; Leclair et al., 1997; Leclair and Bridge, 2001; Bridge, 2003; Leclair, 2002, 2011].

[5] The aim of the present paper is to provide details and results from a new geophysical field technique, the parametric echosounder (PES), which allows high-resolution visualization and quantification of the internal architecture of river dunes. By presenting a unique new high-resolution data set on the internal stratigraphy of alluvial dunes, we demonstrate how new understanding of bed form preservation can be generated, and how PES has the potential to be a significant tool in the study of subsurface sedimentology.

\section{Methods: The PES}

[6] Developed over the last 15 years, the PES was designed as a marine tool to provide high-resolution subsurface images of fine-grained deposits [Wunderlich and Muller, 2003]. The key difference of the PES over traditional linear systems is that it transmits two slightly different high-frequency (both $>100 \mathrm{kHz}$ ) primary signals, which interact to generate two new secondary signals with frequency content equivalent to the sum and difference of the primary signals. The sum, high-frequency, secondary signal (frequency $>200 \mathrm{kHz}$ ) provides data on seafloor depth in the same way as normal linear echosounders. Additionally, the difference of the primary signals provides a low-frequency $(c .1-10 \mathrm{kHz})$ secondary signal capable of penetrating the subsurface to provide data on the stratigraphy in the same manner as a traditional subbottom profiler. The PES has thus proved a popular tool amongst the oceanographic community in a wide range of applications. However, three aspects of the PES capabilities make it uniquely suited for use within fine-grained rivers. First, due to the high system bandwidth of the PES, very short signals can be transmitted without ringing, this meaning that PES can be used in shallow waters (i.e., depths of only $2 \mathrm{~m}$ ) typical of rivers. Second, the small beam width and high-frequency bandwidth result in echoes with steep slopes that can detect small changes of acoustic impedance, thus yielding a high-resolution (i.e., decimeter) signal ideally suited to the study of fluvial bed and bar forms. Third, the PES is very easy to deploy, consisting of a single transducer which is mounted on the hull of the boat. Even high-resolution seismic systems, such as Chirp or Boomer, commonly work off catamarans, which makes them difficult to tow and deploy in shallow water.

[7] The PES used herein was an Innomar SES-2000 Light, which employs a primary frequency of $100 \mathrm{kHz}$, with a selectable lower frequency of $5-15 \mathrm{kHz}$, although $8 \mathrm{kHz}$ was used for this study. The study site was $\sim 9 \mathrm{~km}$ downstream of the confluence between the Río Paraguay and Río Paraná, Argentina, in a $\sim 500 \mathrm{~m}$ wide anabranch channel flowing around a midchannel bar on the west side of the Río Paraná (Figure 1a). At the Río Paraguay-Río Paraná confluence, significant amounts of suspended sediment enter the Río Paraná, with this plume typically moving along the west side of the river before fully mixing [Lane et al., 2008]. However, it should be noted that the study site is always within the influence of the fine-grained material supplied by the Río Paraguay. Ten survey lines $\sim 250 \mathrm{~m}$ long and $10 \mathrm{~m}$ 


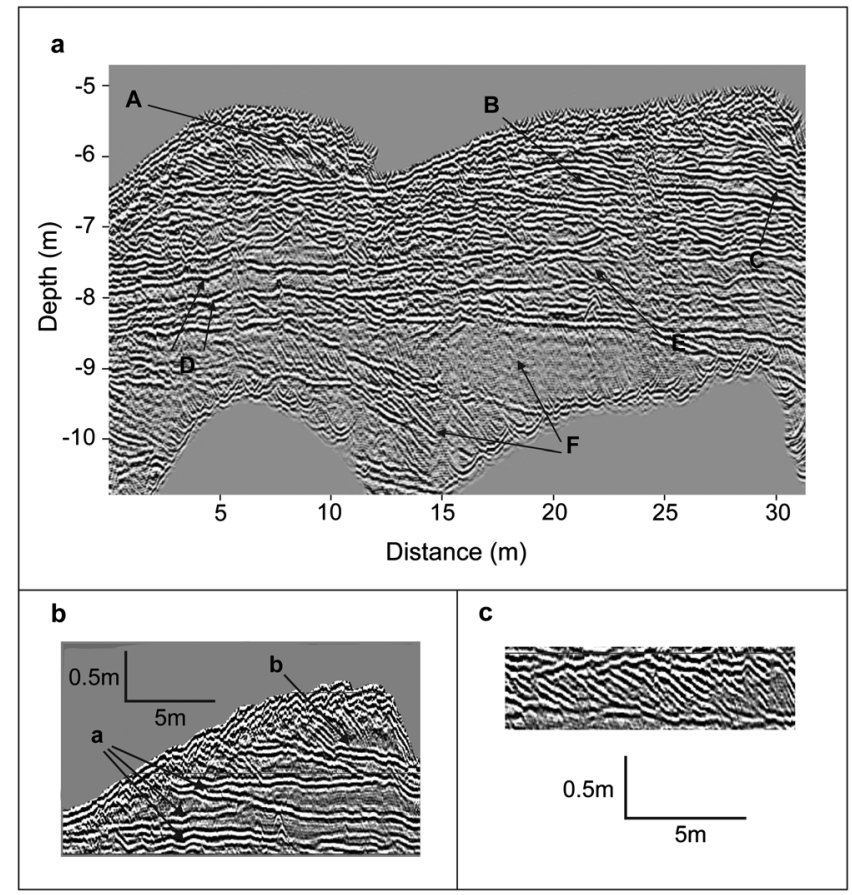

Figure 2. (a) Section of PES survey line showing internal architecture of two dunes at the bed surface and preserved dune and bar cross-strata beneath; labels refer to the following features: A: Internal architecture of active dune, B: coset, $\mathrm{C}$ : reactivation surface, $D$ : bounding surfaces of a dune set, $E$ : preserved dune foresets, F: larger unit bar sets. (b) PES profile of an individual dune at the bed surface showing exceptional resolution of the internal stratigraphy. Note the erosion (bounding) surface between bed forms (labeled a) and individual cross-sets (labeled b). (c) PES profile of preserved dune set, showing the exceptional resolution of the cross-set geometry.

apart laterally were collected over dunes to the west of a small $\sim 1 \mathrm{~km}$ long bar located within the anabranch (Figure 1b). The first return of the PES signal was extracted using Innomar postprocessing software to yield 8720 depth values that were then interpolated within Global Mapper ${ }^{\mathrm{TM}}$ software to provide the bathymetry of the reach from which dune heights were measured $(n=103)$. Channel depth during the surveys varied between $\sim 4 \mathrm{~m}$ near the bar to $\sim 8 \mathrm{~m}$ furthest away from the bar (Figure 1b). Postprocessing included application of a Stolt migration to remove the effects of diffraction hyperbolae, with subsequent visualization and analysis in SMT's Kingdom Suite. A number of measurements of dune set thickness were taken along each set to account for variability within sets $(n=822)$. It should also be noted that only sets in the upper few meters of the PES profiles were included in the analysis. The sets deeper in the profiles (e.g., such as those labeled F in Figure 2a) were much larger than those of the dunes and were interpreted to be the product of unit bar deposition.

\section{Results and Discussion}

\subsection{Performance of the PES}

[8] A central conclusion of this work is that the PES is capable of generating quantitative images of the subsurface with remarkable clarity and resolution, which has allowed collection of a unique data set concerning the dimensions of preserved dune sets. Three features of the subsurface sediment architecture are apparent. First, the PES is able to capture contrasts in subsurface architecture at the decimetric scale (Figure 2) that is comparable with GPR. This resolution allows not only the larger unit bar sets to be imaged, which are seen lower in the profile, but also the individual bounding surfaces of dune cross-stratification from which set thickness can be measured (Figure 2a). Second, the internal architecture of both the active dunes (Figure 2b) and the preserved dune cross-stratification below the active dunes (Figure 2c) can also be quantified. The active dunes show a range of foreset dip angles, presumably in response to variations in bed form migration velocity and/or sediment supply, which are often associated with bed form superimposition and amalgamation [Reesink and Bridge, 2007, 2009]. Third, within the preserved dune sets, individual steep foresets are imaged, as well as reactivation surfaces and lower slopes indicative of cosets (i.e., a group of sets as opposed to an individual set).

\subsection{Analysis of Dune Morphology and Cross-Set Dimensions}

[9] Within the survey area, dune heights ranged from $0.12 \mathrm{~m}$ to $1.57 \mathrm{~m}$, with an average of $0.77 \mathrm{~m}$ (Figure 1c). There was a clear relationship between flow depth and both dune height and wavelength (Figures $1 \mathrm{~b}$ and $3 \mathrm{a}$ ); $\mathrm{H} /$ $\mathrm{d}=0.13$ and $\mathrm{L} / \mathrm{d}=3.7$ where $\mathrm{H}$ is dune height, $\mathrm{L}$ is dune wavelength, and $d$ is flow depth. However, it should be noted that there is significant scatter in the data with $\mathrm{R}^{2}$ values of 0.24 and 0.35 for dune height and wavelength, respectively (Figure 3a). The measurements of individual cross-set thicknesses show a good correlation with the dune dimensions, with smaller sets being preserved beneath the smaller dunes. For example, survey line 2 had the smallest average dune height of $0.62 \mathrm{~m}$ and a corresponding average set thickness of $0.25 \mathrm{~m}$ (preservation ratio $=0.4$ ). Survey line 8 , further away from the bar and into the channel, had the greatest average dune height of $1.08 \mathrm{~m}$ with a corresponding value of $0.32 \mathrm{~m}$ for set thickness (preservation ratio $=0.3$ ). A plot of all dune data and their cross-sets (Figure $3 b$ ) illustrates that the overall preservation ratio (cross-set thickness: dune height) across the ten survey lines was 0.36 , which is very close to the value of 0.30 proposed by Leclair and Bridge [2001]. To further explore the preservation of cross-sets, the dune set thickness was plotted against $d_{i}$, the inferred flow depth (depth below bed surface + water depth at time of survey) (Figure 3c). While not statistically significant, this plot shows a broad trend in average set thickness, which ranges from $0.23 \mathrm{~m}$ for depths $<5.25 \mathrm{~m}$ to $0.36 \mathrm{~m}$ for those $>9 \mathrm{~m}$ depth. Such a trend suggests that the inferred flow depths can be used in this case as a proxy for formative flow depth.

[10] Leclair and Bridge [2001] and Leclair [2011] suggest that mean dune height, $h_{m}$, can be estimated from the mean set thickness, $s_{m}$, by:

$$
h_{m}=2.9( \pm 0.7) s_{m}
$$

[11] Applying this relationship to all the cross-sets gives a mean dune height of $0.88 \mathrm{~m}$ (Figure $3 \mathrm{~b}$ ), which compares well to the mean dune height of $0.77 \mathrm{~m}$ derived from the bed topography (Figures $1 \mathrm{~b}$ and 3a). Additionally, if the height of the dune sets at the inferred flow depths within the subsurface is used to estimate the original dune height 


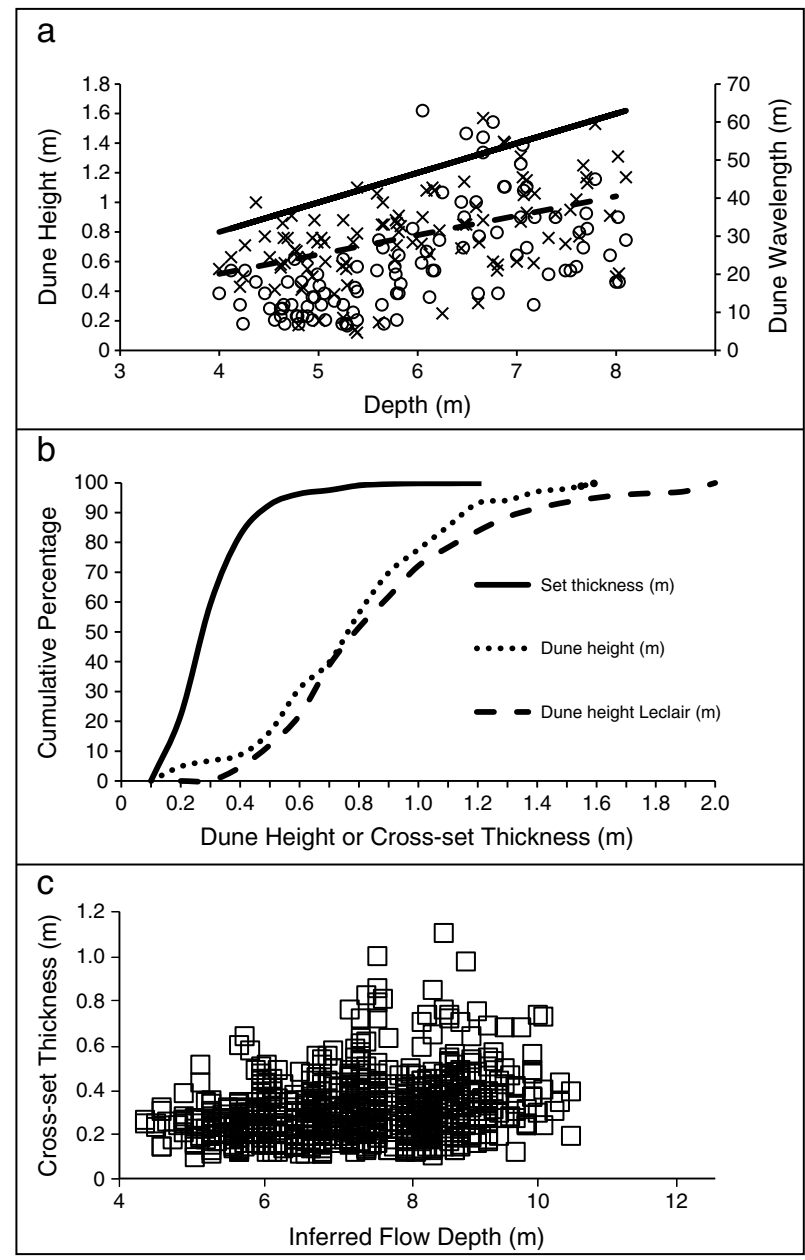

Figure 3. (a) Relationship between flow depth and dune height (gray crosses) and wavelength (open circles). Also plotted are $\mathrm{H} / \mathrm{d}=0.13$ (dash line) and $\mathrm{H} / \mathrm{d}=0.2$ (solid line). (b) Cumulative frequency diagram of dune height and cross-set thickness and inferred dune heights as estimated from set thickness using the relationship of Leclair (2011). (c) Relationship between dune cross-set thickness and inferred flow depth.

$\left(\mathrm{H}_{\mathrm{o}}\right)$, this gives a value of $\mathrm{H}_{\mathrm{o}} / \mathrm{d}_{\mathrm{i}}=0.12$ which also compares well to the measured ratio for the active dunes of 0.13 (Figure 3a).

[12] Given that the measurements of the active dunes were taken at a flow below bankfull, it is also apparent that the dimensions of the dune sets and dune morphology are less than what traditional flow depth: dune height relationships may predict. This observation indicates these bed forms may be adjusted to flow depths other than bankfull, as also reported in other recent field based work on preserved set thickness [Leclair, 2011; Lunt et al., 2013]. The present results also suggest that, although a preservation ratio of 0.3 is a good estimate for dunes (Figure 3b), a more reliable estimate of mean paleochannel flow depth may be obtained by using a value of $\mathrm{H}=0.2 \mathrm{~d}$ (where $\mathrm{H}$ and $\mathrm{d}$ are dune height and mean flow depth, respectively) that represents the upper bound of these data (Figure 3a). These findings have significant implications for scaling relationships and the manner in which dune sets, which are the most ubiquitous sedimentary structure of fluvial deposits, are used to provide inferences on overall sandbody dimensions as used in a range of hydrogeological and petroleum exploration applications [Bridge and Tye, 2000; Ethridge, 2011].

\section{Conclusions}

[13] The study of within-channel depositional processes and products over large spatial areas has remained one of the outstanding challenges within fluvial sedimentology over many years. This lack of data has led to a reliance on experimental and theoretical work that remains to be properly tested in the field. The present results clearly demonstrate the outstanding capabilities and features of parametric echo sounding as a significant tool in the study of contemporary fluvial channels, in much the same way that GPR has proven to be over the past 20 years for subaerially exposed sediments [e.g., Bridge et al., 1998; Fielding et al., 1999; Best et al., 2003; Mumpy et al., 2007; Sambrook Smith et al., 2006, 2009]. GPR has allowed large, pseudo three-dimensional, data sets to be collected from exposed bar sediments that have substantially advanced our knowledge of the links between surface morphodynamics and subsurface product [Best et al., 2003; Mumpy et al., 2007; Sambrook Smith et al., 2006, 2009]. Parametric echo sounding, with its similar resolution to GPR, now provides the potential for similar analyses within channel environments that have hitherto been largely inaccessible. Indeed, by combining dry (GPR) and wet (PES) survey techniques contemporaneously, there is the possibility of quantifying the alluvial architecture of the entire fluvial domain. Additionally, the potential to combine subsurface sedimentary architecture, using PES and GPR, with an analysis of the surface morphology, whether by acoustic sounding, digital photogrammetry or LiDAR techniques, provides further opportunities to establish the relationships between flow, form, and depositional product.

[14] Acknowledgments. This research was supported by UK Natural Environment Research Council grant NE/I015876/1 to GHSS, and funding from the University of Illinois and the Jack and Richard Threet chair in Sedimentary Geology to JLB. JAZ also acknowledges the International Association of Sedimentologists for a contribution towards her field support. We also thank Jens Lowag of Innomar for very helpful advice and discussion on the deployment of the PES.

[15] The Editor thanks Grey Weissman and the anonymous reviewers for their assistance in evaluating this paper.

\section{References}

Best, J. (2005), The fluid dynamics of river dunes: a review and some future research directions, J. Geophys. Res. Earth Surf., F04S02, doi:10.1029/ 2004JF000218.

Best, J. L., P. J. Ashworth, C. S. Bristow, and J. Roden (2003), Three-dimensional sedimentary architecture of a large, mid-channel sand braid-bar, Jamuna river, Bangladesh, J. Sediment. Res., 73, 516-530.

Best, J., P. Ashworth, M. H. Sarker, and J. Roden (2007), The BrahmaputraJamuna River, Bangladesh, in Large Rivers: Geomorphology \& Management, edited by A. Gupta, pp. 395-430, John Wiley and Sons, Chichester.

Bhattacharya, J. P., and R. S. Tye (2004), Searching for modern ferron analogs and application to subsurface interpretation, in The fluvial-deltaic Ferron Sandstone: regional to wellbore scale outcrop analog studies and application to reservoir modeling, AAPG Studies in Geology, edited by T. C. Chidsey, Jr., R. D. Adams, and T. H. Morris, vol. 50, pp. 39-57.

Bridge, J. S. (2003), Rivers and Floodplains; Forms, Processes and Sedimentary Record, Blackwell Publishing, Oxford, pp. 491.

Bridge, J. S., and J. L. Best (1997), Preservation of planar laminae due to migration of low relief bed waves over aggrading upper stage plane beds: comparison of experimental data with theory, Sedimentology, 44, 253-262.

Bridge, J. S., and R. S. Tye (2000), Interpreting the dimensions of ancient fluvial channel bars, channels, and channel belts from wireline-logs and cores, AAPG Bull., 84, 1205-1228. 


\section{SAMBROOK SMITH ET AL.: PARAMETRIC ECHO SOUNDER}

Bridge, J. S., R. E. L. Collier, and J. Alexander (1998), Large-scale structure of Calamus River deposits revealed using ground-penetrating radar, Sedimentology, 45, 977-985.

Bristow, C., J. Pugh, and T. Goodall (1996), Internal structure of aeolian dunes in $\mathrm{Abu}$ Dhabi determined using ground-penetrating radar, Sedimentology, 43, 995-1003, doi:10.1111/j.1365-3091.1996.tb01515.x. Bristow, C. S., S. D. Bailey, and N. Lancaster (2000), The sedimentary structure of linear sand dunes, Nature, 406, 56-59.

Ferret, Y., S. Le Bot, B. Tessier, T. Garlan, and R. Lafite (2010), Migration and internal architecture of marine dunes in the eastern English Channe over 14 and 56 year intervals: the influence of tides and decennial storms, Earth Surf. Processes Landforms, 35, 1480-1493, doi:10.1002/esp.2051.

Fielding, C. R., J. Alexander, and R. McDonald (1999), Sedimentary facies from GPR surveys of the modern, upper Burdekin River of north Queensland, Australia: Consequences of extreme discharge fluctuations, in Fluvial Sedimentology VI, edited by N. D. Smith and J. Rogers, IAS Special Publication, vol. 28 pp. 347-362, Oxford.

Hajek, E. A., and P. L. Heller (2012), Flow-depth scaling in alluvial architecture and nonmarine sequence stratigraphy: example from the Castlegate Sandstone, central Utah, U.S.A, J. Sediment. Res., 82, 121-130.

Lane, S. N., D. R. Parsons, J. L. Best, O. Orfeo, R. A. Kostaschuk, and R. J. Hardy (2008), Causes of rapid mixing at a junction of two large rivers: Rio Parana and Rio Paraguay, Argentina, J. Geophys. Res. Earth Surf., 113, F02019, doi:10.1029/2006JF000745.

Leclair, S. F. (2002), Preservation of cross-strata due to migration of subaqueous dunes: an experimental investigation, Sedimentology, 49, $1157-1180$.

Leclair, S. F. (2011), Interpreting fluvial hydromorphology from the rock record: large-river peak flows leave no clear signature, in From River To Rock Record: The Preservation Of Fluvial Sediments And Their Subsequent Interpretation, edited by S. K. Davidson, S. Leleu, and C. P. North, SEPM Special Publication, vol. 97, pp. 113-123.

Leclair, S. F., and J. S. Bridge (2001), Quantitative interpretation of sedimentary structures formed by river dunes, J. Sediment. Res., 71, 713-716.

Leclair, S. F., J. S. Bridge, and F. Wang (1997), Preservation of cross-strata due to migration of subaqueous dunes over aggrading and non-aggrading beds: comparison of experimental data with theory, Geosci. Can., 24, $55-66$.

Lunt, I. A., G. H. Sambrook Smith, P. J. Ashworth, J. L. Best, S. N. Lane, and C. J. Simpson (2013), Deposits of the sandy braided South Saskatchewan River: Implications for the use of modern analogues in reconstructing channel dimensions in reservoir characterisation, $A A P G$ Bull., 97, 553-576, doi:10.1306/09251211152.

Miall, A. D. (2006), Reconstructing the architecture and sequence stratigraphy of the preserved fluvial record as a tool for reservoir development: A reality check, AAPG Bull., 90, 989-1002.

Mumpy, A. J., H. M. Jol, W. F. Kean, and J. L. Isbell (2007), Architecture and sedimentology of an active braid bar in the Wisconsin River based on 3D ground penetrating radar, in Stratigraphic Analysis Using Ground Penetrating Radar, edited by G. S. Baker and H. M. Jol, pp. 111-132, Geological Society of America, Boulder, Colorado.

Paola, C., and L. Borgman (1991), Reconstructing random topography from preserved stratification, Sedimentology, 38, 553-565.

Reesink, A. J. H., and J. S. Bridge (2007), Influence of superimposed bedforms and flow unsteadiness on formation of cross strata in dunes and unit bars, Sediment. Geol., 202, 281-296.

Reesink, A. J. H., and J. S. Bridge (2009), Influence of bedform superimposition and flow unsteadiness on the formation of cross strata in dunes and unit bars - Part 2, further experiments, Sediment. Geol., 222, 274-300, doi:10.1016/j.sedgeo.2009.09.014.

Sambrook Smith, G. H., P. J. Ashworth, J. L. Best, J. Woodward, and C. J. Simpson (2006), The alluvial architecture and sedimentology of the sandy, braided South Saskatchewan River, Canada, Sedimentology, $53,413-434$

Sambrook Smith, G. H., P. J. Ashworth, J. L. Best, I. A. Lunt, O. Orfeo, and D. R. Parsons (2009), The sedimentology and alluvial architecture of a large braid bar, Río Paraná, Argentina, J. Sediment. Res., 79, 629-642.

Wooldridge, C. L., and E. J. Hickin (2005), Radar architecture and evolution of channel bars in wandering gravel-bed rivers: Fraser and Squamish rivers, British Columbia, Canada, J. Sediment. Res., 75, 844-860.

Wunderlich, J., and S. Muller (2003), High-resolution subbottom profiling using parametric acoustics, Int. Ocean Syst., 7, 6-11. 